\section{Esquema de Restrição Alimentar Altera a Resposta Celular à Insulina em Ratos Diabéticos}

\begin{abstract}
RESUMO
A resistência à insulina é um elemento chave na gênese de várias alterações fisiopatológicas. O esquema de restrição alimentar meal-feeding (MF) consiste na oferta de uma única refeiçấo diária de $2 \mathrm{~h}$, sem, contudo, limitar a quantidade de alimento durante esse período. Este esquema determina várias adaptações morfo-metabólicas, algumas sugerindo maior sensibilidade à insulina. No presente estudo investigou-se, em adipócitos isolados, a sensibilidade à insulina de ratos submetidos a treinamento alimentar e tornados diabéticos (MFD) comparando-os com ratos em livre curso alimentar diabéticos (FFD). A curva dose resposta da captação de 2-deoxi-D-glicose estimulada por insulina sugeriu maior sensibilidade, enquanto a captação máxima foi significativamente maior $(p<0,05)$ nos ratos MFD. Esta maior responsividade à insulina refletiu-se no metabolismo dos adipócitos que mostraram aumento $(p<0,05)$ na

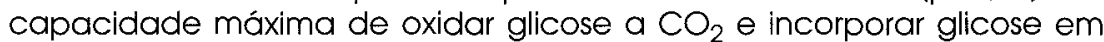
triacilglicerol. O aumento da resposta celular à insulina em ratos MFD refletiu-se in vivo em menor $(p<0,05)$ insulinemia e maior $(p<0,05)$ índice glicose/insulina $(G / \mid)$. Em conjunto, os resultados indicam que o treinamento alimentar melhora a resposta à insulina em ratos diabéticos, o que pode representar uma abordagem alternativa no tratamento do diabetes mellitus. (Arq Bras Endocrinol Metab 2000;44/4: 339-346)
\end{abstract}

Unitermos: Restrição alimentar; Ação da insulina; Diabetes mellitus; Captação de glicose; Oxidação de glicose; Receptor de insulina

\begin{abstract}
Insulin resistance is a key element in the genesis of several pathophysiological changes. Meal feeding (MF) - one daily 2-hour meal, without food restriction in the period - determines several morpho-metabolic adaptations، some of them suggesting enhanced insulin sensitivity. In the present study with isolated adipocytes, we investigated insulin resistance in rats submitted to meal feeding, making them diabetic (MFD). Later, they were compared with diabetic rats under a free feeding diet (FFD). The insulin-stimulated 2-deoxy-D-glucose uptake dose-response curve suggested higher sensitivity, whereas maximum uptake was significantly higher $(p<0.05)$ in MFD rats. This higher sensitivity to insulin had an impact on adipocyte metabolism which showed an increase $(p<0.05)$ in its capacity to oxidize glucose to $\mathrm{CO}_{2}$ and to transform glucose into triacilglicerol. The increase in the cellular response to insulin in MFD rats in vivo resulted in lower insulinemia $(p<0.05)$ and in higher glucose/insulin $(G / 1)$ index $(p<0.05)$. In combination, these results indicate that meal feeding improves insulin response in diabetic rats, which can represent an alternative approach in treating diabetes mellitus. (Arq Bras Endocrinol Metab 2000;44/4: 339-346)
\end{abstract}

Keywords: Food restriction; Insulin action; Diabetes mellitus; Glucose uptake; Glucose oxidation; Insulin receptor

\section{artigo original}

\author{
Doris Hissako Sumida \\ Maristela Mitiko Okamoto \\ Fábio Bessa Lima \\ Ubiratan Fabres Machado \\ Naomi Shinomiya Hell
}

Departamento de Fisiologia e
Biofisica, Instituto de Ciências
Biomédicas, Universidade de São
Paulo (USP), São Paulo, SP.

Recebido em 13/09/1999

Revisado em 18/02/2000 Aceito em 10/04/2000 
A RESISTÊNCIA À INSULINA TEM SIDO considerada um elemento chave na gênese de importantes alterações fisiopatológicas que aumentam tanto a morbidade como a mortalidade dos indivíduos acometidos. $\mathrm{O}$ conjunto destas alterações tem sido referido como "síndrome X" ou "doença plurimetabólica", apresentando um espectro que envolve obesidade, diabetes mellitus, hipertensão arterial, doença cardiovascular aterosclerótica e dislipidemias (1). A investigação das alterações do mecanismo de ação da insulina presentes na resistência, assim como a investigação de protocolos que melhorem a sensibilidade, à insulina representam um passo importante na busca de mecanismos preventivos e / ou curativos para condições relacionadas com a resistência à insulina.

$\mathrm{O}$ esquema de restrição alimentar usualmente denominado de meal feeding ( $\mathrm{MF})$, consiste na oferta de uma única refeição diária de 2 horas, sem restringir a disponibilidade de ração durante esse período, e desenvolve muitas adaptações morfo-metabólicas como, por exemplo: aumento da capacitância gástrica (2), lento esvaziamento gástrico (3), intensificação de processos lipogênicos tanto no tecido hepático $(4,5)$ como no adiposo $(4,6)$, baixa lipomobilização $(2)$, alto conteúdo de glicogênio hepático no período interprandial e resistência a sua depleção $(3,7)$, baixa atividade neoglicogênica hepática $(8)$, aumento da atividade na via glicolítica $(9)$ e maior eficiência alimentar $(3,10,11)$. Muitos desses aspectos falam a favor de sensibilização tecidual às ações da insulina.

Estudos anteriores demostraram que, de fato, os ratos MF exibem alta sensibilidade e responsividade à insulina (resposta confirmada no teste de tolerância à insulina, captação de glicose, oxidação de glicose, incorporação de glicose na molécula lipídica) principalmente no momento da expectativa da refeição habitual $(11,12)$.

Sabendo-se que a restrição alimentar promove um aumento na sensibilidade insulínica, especialmente no metabolismo de carboidratos, tornou-se fundamental averiguar se esse protocolo poderia promover melhora na responsividade à insulina, mesmo na vigência de uma hipoinsulinemia induzida.

\section{MATERIAL E MÉTODOS}

\section{Animais}

Foram estudados ratos Wistar adultos $(2$ meses de idade e peso corpóreo oscilando ao redor de $250 \mathrm{~g}$ no início do experimento), mantidos em ambiente de $12 / 12 \mathrm{~h}$ de claro/escuro (período claro iniciado às 7:00h) e temperatura de $23 \pm 2{ }^{\circ} \mathrm{C}$. Ao iniciar os estu- dos, avaliou-se o peso corporal de cada animal que, em seguida, foi transferido para gaiola individual onde permaneceu $24 \mathrm{~h}$ com disponibilidade plena de água e ração. Após esse período de ambientação, os animais foram divididos $\mathrm{em}$ dois grupos, segundo o esquema alimentar imposto: grupo free-feeding (FF) cuja disponibilidade de ração era sempre plena e $\mathrm{MF}$ alimentado apenas das 8:00 às 10:00h, sem, contudo, limitar a quantidade de ração nessas 2 horas. A quantificação de alimento ingerido foi realizada diariamente e a do peso corpóreo, a intervalos de 3 dias. Este procedimento possibilita o manuseio constante dos animais de modo a reduzir o grau de estresse nos experimentos. Na segunda semana de estudo, os animais (em restrição ou não) foram tornados diabéticos pela injeção intravenosa (veia peniana) de aloxana $(40 \mathrm{mg} / \mathrm{kg}$ p.c. $)$ ministrada sob anestesia com éter, e mantidos por mais 2 semanas em regime alimentar próprio. Neste estudo, os ratos tornaram-se diabéticos não dependentes de insulina. Os experimentos foram realizados às $8: 00 \mathrm{~h}$. Os animais foram sacrificados por decapitação, o sangue foi obtido do tronco cerebral, e o plasma separado para posterior determinação da glicemia e insulinemia.

\section{Isolamento de adipócitos}

Imediatamente após o sacrificio realizou-se laparatomia mediana para remoção do tecido adiposo periepididimal. Os adipócitos foram isolados de acordo com Rodbell (13), com algumas modificações (14). Em resumo, foi retirado o panículo adiposo periepididimal de cada animal, pesado e colocado em $4 \mathrm{~mL}$ de tampão digestivo (D'MEM/HEPES $25 \mathrm{mM} / \mathrm{BSA} 4 \%$, colagenase II $2,0 \mathrm{mg} / \mathrm{mL}, \mathrm{pH} 7,4$ a $37^{\circ} \mathrm{C}$ ). O tecido foi fragmentado com tesoura fina $\mathrm{e}$ incubado por $55 \mathrm{~min}$ $\left(37^{\circ} \mathrm{C}\right)$ sob agitação (180rpm em banho-maria de agitação orbital). Após a digestão, a amostra foi filtrada e lavada três vezes com $25 \mathrm{~mL}$ de tampão EARLE $20 \mathrm{mM}$ contendo soro albumina bovina $1 \%$, piruvato de sódio $1 \mathrm{mM}$, sem glicose, $\mathrm{pH} 7,4$ e mantido a $37^{\circ} \mathrm{C}$ (EARLE "Buffer" - EB). Após a terceira lavagem, a suspensão celular foi deixada $1 \mathrm{~h}$ em banho-maria a $37^{\circ} \mathrm{C}$, com a finalidade de minimizar os efeitos da insulina endógena. Em seguida lavou-se novamente a suspensão celular com o tampão EB e o volume final foi acertado, a fim de se obter um lipócrito de $5 \%$.

\section{Captação de 2-deoxi-D-glicose triciada (3H-2DG) insulino-induzida}

Alíquotas $(450 \mu \mathrm{L})$ de suspensão celular foram pipetadas em tubos plásticos contendo $25 \mu \mathrm{L}$ de insulina fria em concentrações crescentes $(0 ; 0,1 ; 0,2 ; 0,3$; 
0,$5 ; 1,0 ; 2,5 ; 10$ e $25 \mathrm{ng} / \mathrm{mL}$ ) e incubadas por $30 \mathrm{~min}$ a $37^{\circ} \mathrm{C}$, sob agitação horizontal. Pela adição de $25 \mu \mathrm{L}$ de ${ }^{3} \mathrm{H}-2 \mathrm{DG}$ (concentração final de $0,1 \mathrm{mM}$ e $0,15 \mu \mathrm{Ci} /$ tubo) e incubação durante exatos $3 \mathrm{~min}$, avaliou-se a captação de glicose. Para tanto, ao término do terceiro minuto, $200 \mu \mathrm{L}$ da suspensão foram transferidos para tubos de microcentrífuga contendo óleo de silicone (densidade 0,963 ) e foram centrifugados por $5 \mathrm{seg}$. A centrifugação separou 3 fases: uma superior, contendo camadas de células compactadas (pellet celular), uma intermediária, correspondente ao óleo, e a mais interna, constituída pelo tampão aquoso. A fase superior foi separada e mergulhada em frascos contendo $4 \mathrm{~mL}$ de líquido de cintilação para amostras aquosas; a radiação beta emitida foi avaliada em contador beta (Beckman LS-8000). Em outro tubo procedeu-se à incubação de $450 \mu \mathrm{L}$ da mesma suspensão celular com adição de $25 \mu \mathrm{L}$ de $\mathrm{L}-\left[1^{-14} \mathrm{C}\right]$ glicose $(0,1 \mu \mathrm{Ci} /$ tubo $)$ em lugar de ${ }^{3} \mathrm{H}-2 \mathrm{DG}$. Este destinou-se à determinação da incorporação inespecífica.

\section{Ligação da insulina a seus receptores}

A suspensão celular foi transferida para tampão EB de $\mathrm{pH} 7,8$. Alíquotas $(450 \mu \mathrm{l})$ dessa suspensão celular foram incubadas a $15^{\circ} \mathrm{C}$ por $3 \mathrm{~h}$, na presença de $25 \mu \mathrm{L}$ de 125 I-insulina monoiodada (20.000 c.p.m./tubo) e $25 \mu \mathrm{L}$ de insulina "fria" em concentrações crescentes (concentração final: 0,$2 ; 0,3 ; 0,5 ; 1,0 ; 2,5 ; 5,0 ; 10$; $50 ; 100 ;$ e $5.000 \mathrm{ng} / \mathrm{mL}$ ). A esta temperatura, a internalização do complexo insulina-receptor é desprezível (15). Ao final da incubação, $200 \mu \mathrm{L}$ da suspensão celular foram transferidas para tubos de microcentrífuga contendo óleo de silicone e centrifugados por $5 \mathrm{seg}$. A radioatividade do pellet celular foi avaliada no contador gama. A análise de Scatchard (16) foi realizada para calcular o número de receptores e a constante de dissociação aparente $\left(\mathrm{K}_{\mathrm{D}}\right)$ que representa a afinidade do hormônio ao seu receptor.

Nas avaliações acima mencionadas, parte da suspensão celular foi destinada à determinação do volume celular de acordo com DiGirolamo (17), de modo a permitir a expressão dos resultados por área da superfície celular.

\section{Oxidaçāo de D-(U-14C)-glicose a ${ }^{14} \mathrm{CO}_{2}$}

A suspensão celular foi transferida para $\mathrm{o}$ tampão Krebs-Ringer-Bicarbonato de sódio 24,6mM - BSA $1 \%(\mathrm{KRB})$, saturado de $\mathrm{O}_{2} / \mathrm{CO}_{2}(95 \% / 5 \%), \mathrm{pH} 7,4 \mathrm{e}$ temperatura de $37^{\circ} \mathrm{C}$. Aos $450 \mu \mathrm{L}$ de suspensão celular acrescentou-se $25 \mu \mathrm{L}$ de insulina "fria" nas concentrações de 0 e $100 \mathrm{ng} / \mu \mathrm{L}$ e $25 \mu \mathrm{L}$ de $\mathrm{D}$-[U-14C]-glicose $(2 \mathrm{mM}, 0,1 \mu \mathrm{Ci} /$ tubo $)$. Esta mistura foi incubada por $1 \mathrm{~h}$, a $37^{\circ} \mathrm{C}$, sob agitação orbital (150rpm) em tubos plásticos, com tampas de borracha para evitar o escape do carbogênio injetado a cada $15 \mathrm{~min}$. Ao término da incubação, procedeu-se à digestão celular com $\mathrm{H}_{2} \mathrm{SO}_{4} 8 \mathrm{~N}$ para provocar a liberação de $\mathrm{CO}_{2}$ a ser adsorvido em tiras de papel de filtro Whatman \#2 $(2 \times 5 \mathrm{~cm})$ embebidas com $100 \mu \mathrm{L}$ de etanolamina. A transferência destas para um frasco contendo coquetel de cintilação permitiu avaliar em contador beta a radiação emitida (18).

\section{Incorporação de D-(U-14C)-glicose em lipídios}

Para a extração dos lipídios das amostras remanescentes nos tubos do experimento anterior, adicionouse, em cada tubo, $2,5 \mathrm{~mL}$ de reativo de Dole (isopropanol: heptano: $\mathrm{H}_{2} \mathrm{SO}_{4} 8 \mathrm{~N}$, na proporção de 4:1:0,25) e, durante os $30 \mathrm{~min}$ seguintes, esse tubos foram agitados 5 vezes em "vortex". Terminada essa fase, acrescentou-se $1,5 \mathrm{~mL}$ de água destilada $\mathrm{e}$ $1,65 \mathrm{~mL}$ de heptano. Da fase superior dessa mistura, $500 \mu \mathrm{L}$ foram transferidos para um frasco contendo líquido de cintilação para determinação da radioatividade beta acumulada (19).

\section{Procedimentos analíticos}

A glicemia foi quantificada pelo método de glicoseoxidase (Analisa, São Paulo, Brasil) e a insulinemia pelo método radioimunológico (Coat-A-Count, Diagnostic Products Corporation, Los Angeles, USA).

\section{Análise estatística dos resultados}

A avaliação estatística dos resultados foi realizada pelo teste " $t$ " de Student, prefixando-se o nível de significância para $95 \%(\mathrm{p}<0,05)$.

\section{RESULTADOS}

\section{Perfil geral dos animais}

O perfil geral dos animais pode ser visto na tabela 1 . Ao final de 28 dias de observação, os ratos meal-feeding diabéticos (MFD) apresentaram redução de 19,4\% no peso corpóreo e de $50 \%$ na ingestão alimentar em relação aos free-feeding diabéticos (FFD). No momento do sacrificio, as glicemias não diferiram entre os grupos. Por outro lado, a insulinemia do grupo MFD foi estatisticamente inferior à do grupo FFD. A partir dos valores de glicemia e insulinemia, foi calculado o valor do índice $G / I$, um importante índice de sensibilidade à insulina in vipo (20), quanto maior este valor mais insulino-sensivel é considerado o animal. $O$ grupo MFD apresentou valor $\mathrm{G} / \mathrm{I}$ significativamente maior $(p<0,05)$ que o grupo FFD. 
Tabela 1. Perfil geral dos ratos free-feeding diabéticos (FFD) e meal-feeding diabéticos (MFD).

\begin{tabular}{|c|c|c|}
\hline & FFD & MFD \\
\hline $\begin{array}{l}\text { - Peso corpóreo }(\mathrm{g}) \\
\text { inicial } \\
14^{\circ} \mathrm{dia} \\
28^{\circ} \mathrm{dia}\end{array}$ & $\begin{array}{l}235,0 \pm 8,6(21) \\
271,4 \pm 7,4(21) \\
269,2 \pm 6,0(21)\end{array}$ & $\begin{array}{l}251,8 \pm 6,2(20) \\
236,0 \pm 8,0(20)^{*} \\
217,0 \pm 6,0(20)^{*}\end{array}$ \\
\hline $\begin{array}{l}\text { - Ingestão alimentar } \\
\text { inicial } \\
14^{\circ} \text { dia } \\
28^{\circ} \text { dia } \\
\text { - Glicemia }(\mathrm{mg} / \mathrm{dL}) \\
\text { - Insulinemia }(\mu U / \mathrm{mL}) \\
\text { - Índice } G / l\end{array}$ & $\begin{array}{l}19,6 \pm 0,3(19) \\
21,4 \pm 0,6(21) \\
25,8 \pm 1,6(21) \\
285,0 \pm 34,0(21) \\
29,0 \pm 2,9(21) \\
13,3 \pm 2,4(21)\end{array}$ & $\begin{aligned} 6,4 & \pm 0,3(19)^{*} \\
12,1 & \pm 0,5(20)^{*} \\
12,9 & \pm 0,8(20)^{*} \\
273,5 & \pm 33,4(22) \\
14,0 & \pm 0,7(22)^{*} \\
22,4 & \pm 3,6(22)^{*}\end{aligned}$ \\
\hline
\end{tabular}

Os dados são média \pm EPM. Entre parênteses, o número de animais.

${ }^{*} \mathrm{p}<0,05$ vs FFD.

\section{Captação de ${ }^{3} \mathrm{H}-2 \mathrm{DG}$ pelos adipócitos isolados}

$\mathrm{Na}$ figura $1 \mathrm{~A}$ estão representadas as $\mathrm{EC}_{50}$ (concentração hormonal necessária para atingir metade da resposta máxima de transporte) dos ratos MFD e FFD; nesta figura pode-se constatar uma diminuição de $33 \%$ na $\mathrm{EC}_{50}$ dos ratos $\mathrm{MFD}$, que não foi estatisticamente significativa. A figura $1 \mathrm{~B}$ apresenta as curvas doseresposta à insulina e ilustra a tendência do grupo MFD em apresentar deslocamento da curva para a esquerda, com valores de captação mais altos que do FFD. Comparações feitas entre os grupos demonstraram que não houve diferença significativa em relação à captação basal de ${ }^{3} \mathrm{H}-2 \mathrm{DG}$. Entretanto, a captação máxima de ${ }^{3} \mathrm{H}-2 \mathrm{DG}$ e o delta (diferença entre a captação máxima e a basal) foram maiores $(\mathrm{p}<0,05)$ no grupo MFD (figura $\mathrm{lC}$ ).

\section{Oxidação de $\left({ }^{14} \mathrm{C}\right)$-glicose a $\mathrm{CO}_{2}$ pelos adipó- citos isolados}

A capacidade de oxidar glicose estimulada por insulina foi avaliada através da análise da diferença entre o valor basal e o máximo (delta- $\Delta)$, que foi maior $(p<0,05)$ no grupo MFD (figura $2 \mathrm{~A}$ ).

\section{Incorporação de $\left({ }^{14} \mathrm{C}\right)$-Glicose em lipídios pelos adipócitos isolados}

A capacidade de incorporar glicose em lipídios sob estímulo com insulina foi avaliada e o valor de delta da incorporação de $\left[{ }^{14} \mathrm{C}\right]$-glicose foi maior $(\mathrm{p}<0,05)$ no grupo MF (figura 2B).

\section{Ligação da insulina a seus receptores}

A figura $2 \mathrm{C}$ mostra o número de receptores insulínicos $\left(\mathrm{R}_{\mathrm{i}}\right)$ e a constante de dissociação aparente $\left(\mathrm{K}_{\mathrm{p}}\right)$. Não foram observadas diferenças significativas entre os dois grupos estudados.

\section{DISCUSSĀO}

A alteração na disponibilidade energética exerce um importante papel no metabolismo celular. Um balanço energético positivo pode ocasionar alterações fisiopatológicas na ação insulínica, como, por exemplo, na obesidade e no diabetes mellitus tipo 2. Por outro lado, uma restrição alimentar ocasiona profundos efeitos na homeostasia glicídica e na ação insulínica.

Um dos modelos experimentais, estudados no intuito de esclarecer os ajustes metabólicos necessários para um melhor aproveitamento do suprimento energético em condições de baixa disponibilidade de alimento, é o esquema de restrição alimentar $(\mathrm{MF})$, na qual uma única refeição diária é oferecida aos animais. As adaptações morfo-metabólicas apresentadas pelo rato MF, mencionadas anteriormente, sugerem que ocorra, neste modelo experimental, a instalação de mecanismos protetores, capazes de enfrentar um jejum prolongado sem gasto rápido do substrato energético armazenado.

Estudos anteriores demonstraram que a restrição alimentar (meal-feeding) aumenta a sensibilidade e a responsividade celular à insulina em ratos normais $(11,12)$. Com base nestes resultados, averiguouse se a restrição alimentar também poderia ocasionar melhora na responsividade celular à insulina, na vigência de um modelo de diabetes não dependente de insulina, induzido por aloxana.

As comparações realizadas inter-grupos no $28^{\circ}$ dia mostraram que o grupo MFD apresentou uma redução de $19,4 \%$ no peso corpóreo em relação ao FFD, sendo $13 \%$ dessa diferença já detectável antes da indução do diabetes ( $14^{\circ}$ dia de observação), de acordo com o observado em ratos MF não diabéticos (11). Em relação à ingestão alimentar, no $28^{\circ}$ dia a diferença entre MFD e FFD era da ordem de $50 \%$. A par- 
A)

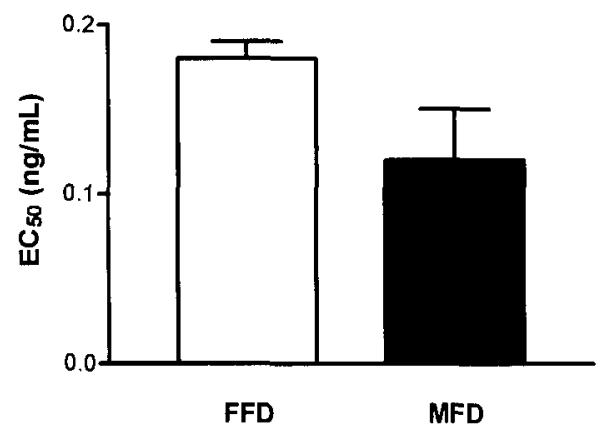

B)

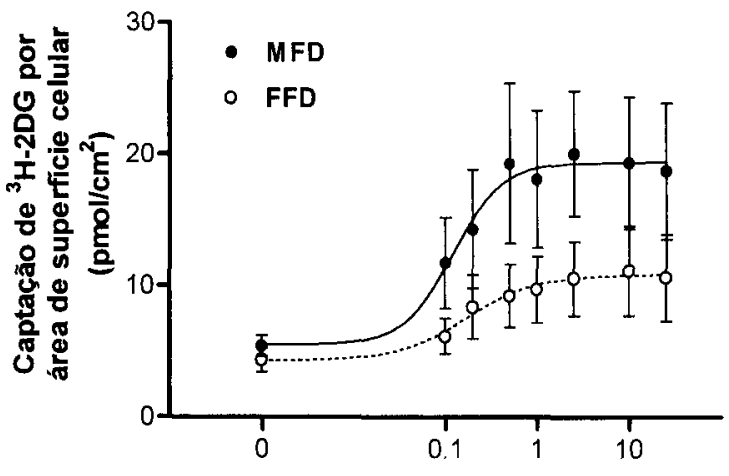

Concentração de insulina (ng/mL)

C)

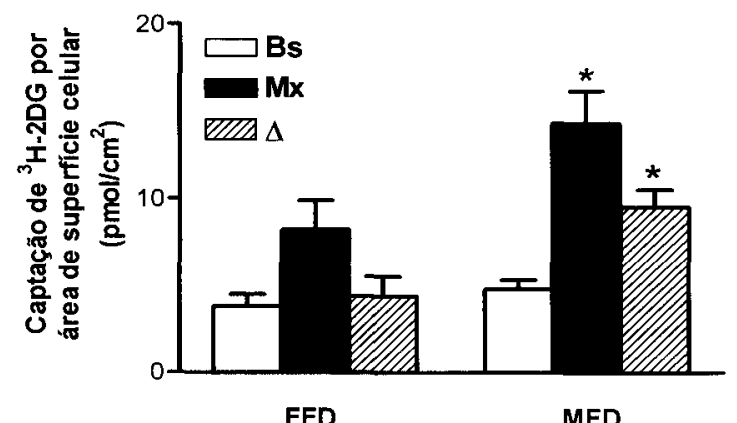

Figura 1. Captação de ${ }^{3} \mathrm{H}-2 \mathrm{DG}$ por área de superficie celular $\left(\mathrm{cm}^{2}\right)$ em adipócitos isolados de ratos free-feeding diabéticos (FFD) e meal-feeding diabéticos (MFD) Em A valores de $E_{50}$ dos grupos FFD e MFD. Em B, curva doseresposta da captação de ${ }^{3} \mathrm{H}-2 \mathrm{DG}$ insulino-estimulada. Em C. resposta basal (Bs), máxima $(\mathrm{Mx})$ e delta $(\Delta)$, da captação de ${ }^{3} \mathrm{H}-2 \mathrm{DG}$. Valores são média \pm EPM de 6 (MFD) a 9 (FFD) experimentos.

${ }^{*} \mathrm{p}<0,05$ vs. FFD.

tir dos resultados acima, pode-se observar que o déficit de $50 \%$ na quantidade de ingestão provocou, no $\mathrm{MF}$, um comprometimento no peso corporal de apenas $19,4 \%$. Parece, portanto, que o aumento no índice de eficiência alimentar já descrito $(2,21-23)$ contribuiu para impedir um emagrecimento excessivo.
A)

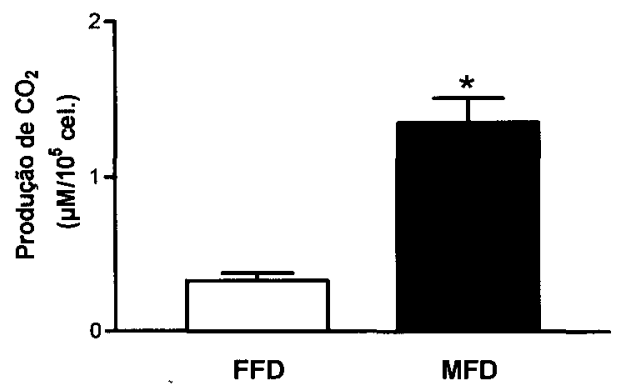

B)

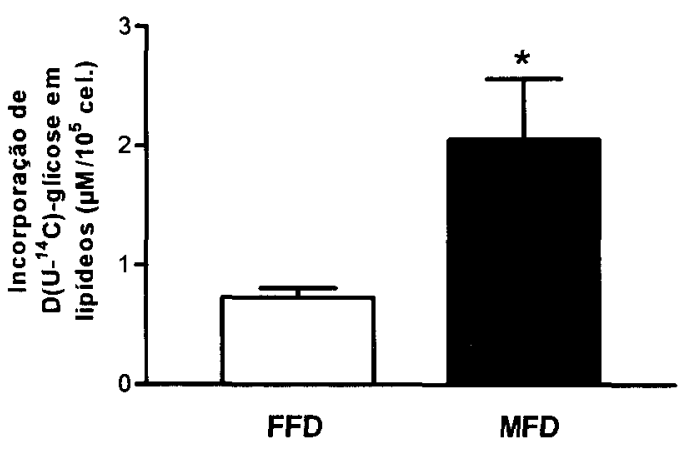

C)

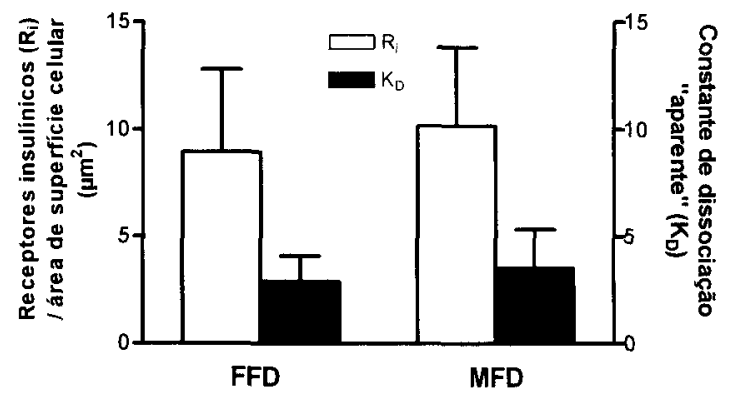

Figura 2. Teste de oxidação de D-(U-14 $\mathrm{C})$-glicose a ${ }^{14} \mathrm{CO}_{2}$ incorporação de D-(U-14C)-glicose em lipídios e ligação da insulina a seus receptores, em adipócitos isolados de ratos freefeeding diabéticos (FFD) e meal-feeding diabéticos (MFD). Em A valor de delta ( $\Delta$ - diferença entre o valor máximo e basal) da oxidaçāo de D-(U-14 C)-gilicose a ${ }^{14} \mathrm{CO}_{2} \mathrm{Em} \mathrm{B}$, valor de delta da incorporação de D-(U-14 C)-glicose em lipídios. Em C. número de receptores insulínicos $\left(R_{j}\right)$ por área $\left(\mu \mathrm{m}^{2}\right)$ de superficie celular e constante de associação "aparente" $\left(K_{D}\right)$. Os dados são média \pm EPM de 6 (MFD) a 9 (FFD) experimentos. ${ }^{*} p<0,05$ vs. FFD.

As glicemias não diferiram entre os dois grupos. Por outro lado, a insulinemia do grupo MFD apresentou valores mais baixos e o índice $\mathrm{G} / \mathrm{I}$ apresentou-se aumentado, indicando maior sensibilidade insulínica in vivo.

É sabido que a insulina deve, agudamente, promover a captação de glicose em tecidos insulino-sen- 
síveis pelo aumento da velocidade máxima de transporte, envolvendo aumento no número de transportadores funcionais de glicose $(24,25)$. Por esta razão, foi escolhido o teste de captação de ${ }^{3} \mathrm{H}-2 \mathrm{DG}$ para averiguar a sensibilidade e a responsividade das células adiposas à insulina. $\mathrm{O}$ análogo de glicose, 2-desoxi-Dglicose, foi escolhido por ser um substrato que é captado e fosforilado pelos mesmos processos da D-glicose, sem contudo sofrer metabolização pela célula (26). Na quantificação da radioatividade inespecífica utilizou-se a L-glicose, pois a membrana celular é relativamente impermeável a esse análogo. A curva doseresposta à insulina da captação da ${ }^{3} \mathrm{H}-2 \mathrm{DG}$ do grupo MFD sugeriu um deslocamento à esquerda, o qual não foi estatisticamente confirmado na análise da $\mathrm{EC}_{50}$. Por outro lado, o MFD apresentou capacidade máxima de captação da ${ }^{3} \mathrm{H}-2 \mathrm{DG}$ e incremento $(\Delta)$ maiores que os do FFD, o que foi interpretado como maior responsividade do MFD à insulina.

O grupo MFD apresentou menor insulinemia que o FFD e aumento da resposta à insulina, o que poderia ser esperado caso ocorresse, por exemplo, o fenômeno de up regulation dos receptores insulínicos. Up ou down regulation dos receptores pode ocasionar alteração nos processos de translocação de transportadores de glicose para a membrana plasmática (27), modificando a resposta celular ao hormônio. Para testar essa hipótese, realizou-se o teste de binding de insulina aos receptores específicos; os resultados demonstraram que a alteração na sensibilidade e na responsividade celular à insulina não se devem ao aumento do número ou afinidade dos receptores de insulina. É possível inferir, portanto, que o aumento na resposta celular à insulina, observado no animal cronicamente adaptado ao esquema de restrição, se deva a modificações nos eventos pós-receptores, entre os quais destaca-se aumento na quantidade de GLUT4 , bem como na sua translocação para a membrana plasmática $(28,29)$. Outra possibilidade seria a ocorrência de maior fosforilação de IRS- $1 / 2$, já que estes substratos, quando fosforilados, apresentam grande afinidade por proteínas com domínio $\mathrm{SH}_{2}(30)$. Essas proteínas têm sido responsabilizadas por importantes processos intracelulares, entre os quais se destaca a ativação da expressão gênica de outras proteínas, ativação de diversas vias metabólicas, etc. Uma dessas proteínas é a fosfatidil-inositol 3'-cinase (PI3K), cujo envolvimento com o processo de translocação do GLUT4 para a membrana plasmática já foi demonstrado (31).

$\hat{E}$ bem conhecido que a insulina estimula várias enzimas da via glicolítica e da via lipogênica, além de ativar a lipase de lipoproteínas e inibir a atividade da lipase hormônio-sensível. Já foi demonstrado que a insulina aumenta a oxidação de ${ }^{14} \mathrm{C}$-glicose a ${ }^{14} \mathrm{CO}_{2}$ em adipócitos isolados (32), assim como aumenta a incorporação de ${ }^{14} \mathrm{C}$-glicose em lipídios (33). Considerando-se que o esquema de restrição alimentar aumenta a captação de glicose nos adipócitos isolados, investigou-se as respostas insulino-induzidas de oxidação de glicose e incorporação desta em moléculas de triacilglicerol. Os incrementos (D) obtidos foram maiores no grupo MFD, mostrando, mais uma vez, que este grupo é mais responsivo à insulina que o FFD. A lipogênese mais intensa do esquema MF provavelmente contribuiu para evitar a perda excessiva do peso corporal e representaria um aspecto do fenômeno genericamente denominado de aumento da eficiência alimentar.

É sabido que em camundongos (34), macacos $(35,36)$ e ratos (37-39), a restrição alimentar prolonga significantemente a longevidade da espécie. Em ratos MF $(40)$ e camundongos $(33,41)$, a incidência tumoral diminui com a imposição do meal feeding. No presente estudo, foi demonstrado que ratos sob meal feeding manifestam alta responsividade celular à insulina mesmo no estado diabético. Portanto, é possível que a modalidade alimentar de disciplinar o horário da refeição, restringindo o tempo de consumo, constitua uma conduta alternativa a ser acoplada a outras abordagens terapêuticas para o diabetes mellitus, principalmente por melhorar a resposta dos tecidos periféricos à insulina.

\section{REFERÊNCIAS}

1. De Fronzo RA, Ferranini E. Insulin resistance. A multifaceted syndrome responsible for NIDDM, obesity, hypertension, dyslipidemia, and atherosclerotic cardiovascular disease. Diabetes Care 1991;14:173-94.

2. Curi R, Hell NS. Metabolic changes of twenty weeks food-restriction schedule in rats. Physiol Behav 1986;36:239-43.

3. Lima FB, Hell NS, Timo-laria C, Dolnikoff MS, Pupo AA. Carbohydrate metabolism and food intake in food restricted rats: effects of an unexpected meal. Physiol Behav 1982;29:931-7.

4. Hollifield $G$, Parson W. Metabolic adaptations to a "stuff and starve" feeding program. II. Obesity and the persistence of adaptive changes in adipose tissue and liver occurring in rats limited to a short daily feeding period. J Clin Invest 1962:41:250-3.

5. Tepperman J, Tepperman HM. Effects of antecedent food intake pattern on hepatic lipogenesis. Am J Physiol 1958:193:55-64.

6. Levelle GA. Lipogenesis in adipose tissue of meal-fed rats. A possible regulatory role of $\alpha$-glycerophosphate formation. Can Physiol Pharmacol 1967:45:201-14. 
7. Hell NS, Oliveira LBC, Dolnikoff MS, Scivoletto R, Timolaria $C$. Changes of carbohydrate metabolism caused by food restriction, as detected by insulin administration. Physiol Behav 1980;24:473-7.

8. Leveille GA, Chakrabarty K. In vivo and in vitro studies of gluconeogenesis in meal-fed and nibbling rats. J Nutr 1968;96:397-402.

9. Sugden MC, Grimshaw RM, Holness MJ. The regulation of hepatic carbon flux by pyruvate dehydrogenase and pyruvate dehydrogenase kinase during long-term food restriction. Biochem J 1993;296:217-23.

10. Leveille GA. Adipose tissue metabolism: influence of periodicity of eating and diet composition. Fed Proc 1970;29: 1294-301.

11. Sumida $\mathrm{DH}$. Sensibilidade celular à insulina decorrente do esquema de restrição alimentar em ratos adultos normais e diabéticos. São Paulo, 1996. 88p. (Dissertaçāo de mestrado - Instituto de Ciências Biomédicas da Univ. de São Paulo].

12. Lima FB, Matsushita DH, Hell NS, Dolnikoff MS, Okamoto MM, Cipolla-Neto J. The regulation of insulin action in isolated adipocytes. Role of the periodicity of food intake, time of day and melatonin. Braz J Med Biol Res 1994:27:995-1000.

13. Rodbell M. Metabolism of isolated fat cells. Effects of hormones on glucose metabolism and lipids. J Biol Chem 1964:239:357-80.

14. Lima FB, Machado UF, Seraphim PM, Sumida DH, Moraes SMF et al. Pinealectomy causes glucose intolerance and decreases adipose cell responsiveness to insulin in rats. Am J Physiol 1998;275:E934-41.

15. Garvey WT, Olefsky JM, Marshall S. Insulin induces progressive insulin resistance in cultured rat adipocytes: sequential effects at receptor and multiple post-receptor sites. Diabetes 1986;35:258-67.

16. Scatchard $G$. The attractions of proteins for small molecules and ions. Ann NY Acad Sci 1949;51:660-72

17. DiGirolamo M. Medlinger S, Fertig JW. A simple method to determine cell size and number in four mammalian species. Am J Physiol 1971:221:850.

18. Rodbell M. Metabolism of isolated fat cells. Effects of hormones on glucose metabolism and lipids. J Biol Chem 1964;239:357-80.

19. Dole VP, Meirnertz H. Microdetermination of long chain fatty acids in plasma and tissues. J Biol Chem 1960;235:2595-9.

20. Caro JF. Insulin resistance in obese and nonobese man. $\mathrm{J}$ Clin Endocrinol 1991:73:691-6.

21. Leveille GA, Hanson RW. Influence of periodicity of eating on adipose tissue metabolism in the rat. Can J Phisiol Pharmacol 1965:43:857-68.

22. Leveille GA, O'Hea EK. Influence of periodicity of eating on energy metabolism in the rat. J. Nutr 1967:93:541-5.

23. Curi R, Hell NS, Bazotte RB, Timo-laria C. Metabolic performance of free fed rats subjected to prolonged fast as compared to the metabolic pattern in rats under long term food restriction. Physiol Behav 1984;33:25-31.

24. Olefsky JM. Effect of dexamethasone on insulin binding, glucose transport, and glucose oxidation of isolated rat adipocytes. J Clin Invest 1975,56:1499-508.

25. Olefsky JM, Kobayashi M. Ability of circulating insulin to chronically regulate the cellular glucose transport system. Metabolism 1978;27:917-29.

26. Wick NA, Drury DR, Hakada HI, Wolfe JB. Localization of the primary metabolic block produced by 2-deoxyglucose. J Biol Chem 1957:224:963-9.

27. Gliemann J, Gammeltoft S, Vinten J. Time-course of insulin-receptor binding and insulin induced lipogenesis in isolated rat fat cell. J Biol Chem 1975;250:3368-74.

28. Sumida DH, Machado UF. Papel do GLUT 4 na sensibilidade celular à insulina. XXIII Congresso Brasileiro de Endocrinologia e Metabologia / III Congresso Paulista de Endocrinologia e Metabologia, São Paulo, 1998, p S295.

29. Sumida DH, Bessa FA, Okamoto MM, Machado UF. Increased adipocyte insulin sensitivity induced by mealfeeding schedule involves changes in the insulin signal transduction and enhancement of GLUT 4 gene expression. Diabetes 1999;48 (suppl. 1):A266.

30. Araki E, Lipes MA, Patti MA, Bruning JC, Haag B, Jonhnson RS et al. Alternative pathway of insulin signaling in mice with target disruption of the IRS-1 gene. Nature 1994;372:186-90.

31. Okada T, Kawano Y, Sakakihara T, Hazek O, UI M. Essential role of phosphatidylinositol-3-kinase in insulininduced glucose transport and antilipolysis in rat adipocytes. Studies with a selective inhibitor wortmannin. J Biol Chem 1994:269:3568-73.

32. Olefsky JM. The effects of spontaneous obesity on insulin binding, glucose transport, and glucose oxidation of isolated it adipocytes. J Clin Invest 1976:57:842-51

33. Moon CK, Lee HL, Lee MO, Kim SG. Effects of Brazilin on glucose oxidation, lipogenesis and threin involved enzymes in adipose tissues from diabetic kk-mice. Life Sci 1993;53:1291-7.

34. Nelson W, Scheving L, Halberg F. Circadian rhythms in mice fed a single daily meal at different stages of lighting regimen. J Nutr 1975; 105:171-84.

35. Kemnitz JW, Roecker EB, Weindruch R, Elson DF, Baum ST, Bergman RN. Dietary restriction increases insulin sensitivity and lowers blood glucose in rhesus monkeys. Am J Physiol 1994;266:E540-7.

36. Lane MA, Reznick AZ, Tilmont EM, Lanir A, Ball SS, Read $V$, et al. Aging and food restriction aiter some indices of bone metabolism in male rhesus monkeys (Macaca mulatta). J Nutr 1995; 125:1600-10.

37. Leveille GA. The long-term effects of meal-eating on lipogenesis enzyme activity, and longevity in the rat. $J$ Nutr 1972;102:549-56.

38. Masoro EJ, Shimokawa I, Higami Y, Mcmahan CA, Yu BP Temporal pattern of food intake not a factor in the retardation of aging processes by dietary restriction. J Gerontol Biol Sci 1995;50A(1):B48-53. 
39. Nichols NR, Fench CE, Nelson JF. Food restriction delays the age-related increase in GFAP mRNA in rat hypothalamus. Neurobiol Aging 1995:16:105-10.

40. Roebuck BD, Baumgartner KJ, Macmillan DL, Caloric Restriction and Intervention in Pancreatic Carcinogenesis in the Rat. Cancer Res 1993;53:46-52.

41. Volk MJ, Pugh TD, Kim M, Frith CH, Daynes RA, Ershler WB, et al. Dietary restriction from middle age attenuates age-associated lymphoma development and inter- leukin 6 dysregulation in C57BL/6 Mice. Cancer Res 1994;54:3054-61.

\section{Endereço para correspondência:}

Ubiratan Fabres Machado

Depto. de Fisiologia e Biofísica, ICB/USP

Av. Prof. Lineu Prestes 1524

05.508-900 São Paulo, SP

Fax: (011) 818-7285 